\title{
BMJ Open Postnatal consultations with an obstetrician after critical perinatal events: a qualitative study of what women and their partners experience
}

\author{
Stinne Høgh (D) , ${ }^{1}$ Laura Emdal Navne (D) , ${ }^{2,3}$ Marianne Johansen, ${ }^{1}$ \\ Mette Nordahl Svendsen, ${ }^{3}$ Jette Led Sorensen ${ }^{4}$
}

To cite: Høgh S, Navne LE, Johansen M, et al. Postnatal consultations with an obstetrician after critical perinatal events: a qualitative study of what women and their partners experience. BMJ Open 2020;10:e037933. doi:10.1136/ bmjopen-2020-037933

- Prepublication history for this paper is available online. To view these files, please visit the journal online (http://dx.doi. org/10.1136/bmjopen-2020037933).

Received 21 February 2020 Revised 03 July 2020 Accepted 17 July 2020

\section{Linked}

- http://dx.doi.org/10.1136/ bmjopen-2020-037932

Check for updates

(C) Author(s) (or their employer(s)) 2020. Re-use permitted under CC BY-NC. No commercial re-use. See rights and permissions. Published by BMJ.

For numbered affiliations see end of article.

Correspondence to

Dr Stinne Høgh;

stinne.hoegh@regionh.dk

\section{ABSTRACT}

Objective The objective of this study was to explore women's and their partners' experiences with attending postnatal consultations with an obstetrician after critical perinatal events.

Design Qualitative interview study. We did semistructured individual narrative interviews exploring the lived experiences. Interviews were analysed using a phenomenological approach and the thematic analysis was validated by a transdisciplinary group of anthropologists, obstetricians and a midwife.

Setting Department of obstetrics at a large hospital in Denmark.

Participants We did a qualitative study with 17 participants (10 women and 7 partners) who had experienced critical perinatal events.

Results Five major themes were identified: (1) a need to gain understanding and make sense of the critical perinatal events, (2) a need for relational continuity, (3) the importance of discussing emotional effects as well as physical aspects of occurred events, (4) preparing for future pregnancies and (5) closure of the story. Most of the participants emphasised the importance of knowing the obstetrician undertaking the postnatal consultation. The majority of the participants described a need to discuss the emotional effects of the experience as well as the physical aspects of occurred events. The postnatal consultation served as an approach to obtain a positive closure of their birth story and to feel confident about potential future pregnancies.

Conclusions This interview-based study suggests that postnatal consultation with an obstetrician might be an important tool for women and their partners in understanding the course of events during the critical birth experience and in processing it and preparing for future pregnancies. It appears to be important to assign an obstetrician whom they already know and to encourage them to discuss not only physical aspects of what happened but also the emotional effects of the experience.

\section{INTRODUCTION}

In several countries the health authorities recommend that all women are given an opportunity to review their birth experiences with healthcare professionals and to
Strengths and limitations of this study

- Short time interval from the postnatal consultation to the interview enhancing the participants' ability to recall their experiences.

- The women and their partners were interviewed individually in separate rooms, providing space for their own uninterrupted narrative.

- Findings were validated in a transdisciplinary group enhancing the reflexivity and validity of the study.

Data collected in this study were from a heterogeneous group and did not target all potential perinatal complications.

ask questions about the care they received during labour to elucidate issues that may have consequences for the mother and/or the child. ${ }^{1-3}$ According to Danish guidelines on complicated perinatal events, it is recommended that couples are offered a consultation with an obstetrician to clarify the course of events and to council on potentially subsequent pregnancy and childbirth. ${ }^{1}$ However, the frequency of postnatal consultations appears to be decreasing. ${ }^{4}$ Due to earlier postnatal discharge, ${ }^{5}$ women may not have had an opportunity to talk to a healthcare professional directly involved in their care before discharge, possibly amplifying the need for a postnatal consultation.

Women who survive critical perinatal events may experience shock, loss of control or disempowerment in relation to the critical perinatal events. ${ }^{6-8}$ Furthermore, women who experience critical perinatal events have an increased risk of postnatal depression and post-traumatic stress. ${ }^{9}{ }^{10}$ Support from the partner plays an important role in women's perinatal mental health. ${ }^{11} 12$ Studies on partners' experiences of critical perinatal events found that it had an impact on their mental 
health beyond the birth and identified a need for support and someone to talk to. ${ }^{13} 14$

A recent Cochrane review found no evidence to support routine debriefing for the prevention of psychological trauma following childbirth in women who perceived giving birth as psychologically traumatic. ${ }^{15}$ Intriguingly, research on midwifery postnatal consultations showed that the majority of women had a need for a postnatal consultation, preferably with the midwife and/ or the obstetrician who had attended the birth. ${ }^{16}$ Women described the midwifery postnatal consultation as a way to fully understand the course of events and the birth experience, ${ }^{416}$ and that it also had improved their recovery. ${ }^{17}$ In addition, women who were not offered postnatal consultations felt abandoned and were left with unanswered questions. ${ }^{17}$ The partners also emphasised a need for information and dialogue but were often not met in their needs, and described a feeling of being marginalised because of a mother-baby focus. ${ }^{12}{ }^{18}$ Although there is no evidence of reducing psychological trauma, it seems like there is a need for a postnatal consultation following a traumatic childbirth.

To our knowledge no study has previously examined the experiences of postnatal consultations with an obstetrician (ObPostCons). Hence, the objective of this study was to expand on previous research by exploring women's and their partners' experiences with ObPostCons.

\section{MATERIAL AND METHODS}

Data from these interviews are reported in two different papers, that in addition to the aim of this study, explored the women's and their partners' experience of critical perinatal events. We did a narrative interview study to access the way in which the women and partners ordered and gave meaning to their experiences. ${ }^{19} 20$

The study comprised women with critical perinatal events from a large hospital in Denmark. The hospital serves low-risk women living in Copenhagen as well as being a national tertiary referral centre. The hospital had 5366 deliveries in 2018, ${ }^{21}$ of which 146 women had an ObPostCons. Currently, no formal criteria for referring to an ObPostCons exist. It mostly depends on the obstetrician or healthcare professional involved. Women or their partners can always request an ObPostCons if they need a review or debriefing of their birth events. ObPostCons are always conducted by an experienced specialised obstetrician.

Convenience sampling was used for this study. ${ }^{22}$ Eligible study participants were women referred to an ObPostCons after critical perinatal events as defined by either healthcare staff or the woman/her partner had requested one. The exclusion criteria were cases of perinatal death, lack of informed consent and non-Danish or non-English speaking.

Auxiliary nurses in the outpatient clinic informed eligible study participants about the study and invited them to participate, providing them with an information letter when attending the clinic for the scheduled ObPostCons. Women who agreed to enrol in the study provided written consent to share their medical data and gave their permission to be contacted by phone by the authors $(\mathrm{SH}$ or LEN) to schedule an interview. Two women $(2 / 12)$ declined to participate. Invited women were asked to also ask their partner for permission to contact them by phone.

Data from medical records were used for socioeconomicrelated and birth-related factors on the interviewed women. For partners only data on age and ethnicity were collected.

The study participants were interviewed separately, in order to give room for their individual voices and experiences, 1-10 months after the ObPostCons in the period from August to November 2018. Written consent was obtained from all participants. Most interviews took place in the participants' homes, but two were, on request, conducted in the outpatient clinic and one at the participant's workplace.

The first (SH) and second author (LEN) conducted the interviews. None of the interviewers had a professional or personal relationship with the participants.

Interview themes (table 1) were based on existing literature on the experiences of women and their partners after critical perinatal events, ${ }^{681417}$ including anthropological studies on postnatal experiences with premature birth, ${ }^{23}{ }^{24}$ and field study observations of five ObPostCons conducted by the second author prior to this study. The narrative interviews were always opened with the phrase: 'Please tell us your story about pregnancy and birth, where you think it all begins...' to learn how the participants ordered and constructed their experience.

Theoretically the study originated from a phenomenological tradition, exploring human experience and sense-making. ${ }^{25}$ The narrative interview provided access to the meaning the women and partners attributed to the critical events. This meaning reflected the expectations and understandings they had gained through participating in the critical events. ${ }^{19}$ Thus, when interviewing the participants, we were curious as to how they would share their experience with us in an interview setting. We paid special attention to specific details on social, temporal and specific indicators of an event to learn what was important in the participants' story and experience. ${ }^{19}$

The interviews lasted between $30 \mathrm{~min}$ and 2 hours and were audiotaped and transcribed ad verbatim. Originally, the interviews were conducted and transcribed in Danish, except for two with English-speaking participants. The Danish quotes were translated into English by a professional bilingual language service provider and were checked for accuracy by the interviewers (SH and LEN).

\section{Data analysis}

To obtain a general comprehensive impression of the collected information, the interviews were read through several times ${ }^{22}$ and examined using thematic analysis. Through reading, critical reflection and immersion in the 
Table 1 Narrative interview theme-guide in postnatal consultations with an obstetrician after critical perinatal events: a qualitative study of what women and their partners experience

The aim of the study, voluntary participation, possible to withdraw, tape recording, anonymity, how interview data will be Introduction reported, optional reading of publication draft

$\begin{array}{ll}\text { Opening } & \text { Please tell us your story about pregnancy and } \\ \text { question } & \text { birth, where you think it all begins... } \\ \text { Fixpoints } & \text { Expectations } \\ & \text { Experience } \\ & \text { Social interactions and relations } \\ & - \text { Staff } \\ & - \text { Partner } \\ & - \text { Child } \\ & \text { Organisation Emergency, during } \\ & \text { admittance, transfers between } \\ & \text { departments/wards (antenatal ward, } \\ & \text { delivery ward, postnatal ward, operating } \\ & \text { room, ICU, NICU or other) } \\ - & \text { Reactions from family and friends } \\ - & \text { Postnatal consultation } \\ & - \text { Expectations } \\ & - \text { What was it about? } \\ & - \text { Experiences of the communication } \\ & - \text { What did you get out of it? } \\ & - \text { Suggestions for adjustments } \\ & \text { Retrospective rationalisations } \\ & \text { Thoughts about the future-future } \\ & \text { pregnancies and births } \\ & \text { Questions and missing points } \\ & \text { Thank you }\end{array}$

ICU, intensive care unit; NICU, neonatal intensive care unit.

text, we found connections in the data, which was coded manually for first-order and second-order themes. ${ }^{22} 26$ During the third reading of the interviews, these themes were compared with the original themes in the interview guide. We wanted to remain open towards new themes appearing in the initial analytic phase and then relate the findings to our original interests to see how they differed. Throughout the readings, we were interested in the contextualising, the chronology, the transformative elements and the performance of the stories. ${ }^{22}$ Involving researchers from different professions in designing the study, creating the interview guide and analysing the data ensured any preunderstanding was accounted for and that most aspects were covered. All authors read the transcripts and met to discuss what themes each of us had identified as central in order to illuminate blind spots in the analysis process. All participant names were changed to pseudonyms.

\section{Patient and public involvement}

The study was conceived as a patient involvement initiative. Women's and partners' voices are generally missing in the literature on critical perinatal events. Methodologically, this project also took a patient-involving approach. Using narrative interviews, this project aimed at bringing the women's and their partners' narratives to the fore.

\section{RESULTS}

We conducted 17 narrative interviews with 10 women and 7 partners. Two partners declined participation, and one woman did not have a partner. Nine women/partners were referred to the ObPostCons by the healthcare staff and one had requested it herself. All the women attended the ObPostCons whereas only four out of seven partners did.

The majority of the partners expressed no need to attend an ObPostCons, however, some believed it would be valuable. One reason for no need of an ObPostCons was that the wife was doing mentally and physically fine at the time. Another partner was unfortunately preoccupied with work on the day of the ObPostCons. Two partners attended the ObPostCons because they knew it was important to their partners.

I think it was important to have it (the ObPostCons) for Lily's sake. But for me personally, it was more like, well, our baby is out and he's doing all right. (James)

Most women had high educational degrees, were between 26 and 35 years of age and were of Danish origin (table 2). They had experienced a wide range of obstetrical conditions (table 3) and their history of obstetrics differed (table 2).

The analysis of the interviews identified five themes: (1) a need to gain understanding and make sense of the critical perinatal events, (2) a need for relational continuity, (3) the importance of discussing emotional effects as well as physical aspects of occurred events, (4) preparing for future pregnancies and (5) closure of the story.

\section{A need to gain understanding and make sense of the critical perinatal events}

The timing of the ObPostCons, which was scheduled 1-3 months postpartum, did not necessarily live up to the participants' preferences. It depended greatly on their situation when they were mentally prepared to attend.

I think it's fine having it after a month. Two months could be o.k. I mean, you might be more adjusted; I mean, having time to process what happened, you know. Having it earlier would be too soon. It would be, like, you'd only just have come home at that stage. (Lily)

I think two months was a long time to wait for the information. Of course, I was more willing to talk about it and I could understand the information better two months later, that's true. But yes, I'd rather have it as soon as possible. (Elizabeth)

Most of the women began their stories with an uncertainty about what the purpose of the ObPostCons was. 
Table 2 Sociodemographic characteristics of the interviewed women

\begin{tabular}{ll}
\hline Characteristics & Number of women \\
\hline $\begin{array}{l}\text { Age (years) } \\
\leq 25\end{array}$ & 1 \\
$26-35$ & 7 \\
$>35$ & 2 \\
\hline Gestational age at time of birth & \\
$<30$ & 4 \\
\hline $30-36^{+6}$ & 2 \\
$37-42$ & 4 \\
\hline Parity & \\
\hline Nulliparous & 7 \\
\hline Multiparous & 3 \\
\hline Comorbidity* & \\
\hline Yes & 4 \\
\hline No & 6 \\
\hline Cohabitation with spouse & \\
\hline Yes & 8 \\
\hline No & 2 \\
\hline
\end{tabular}

Maternal education

\begin{tabular}{|cc}
\hline Advanced degree & 5 \\
\hline $3-4$ years higher degree & 3 \\
$1-2$ years higher degree & 1 \\
\hline Missing & 1 \\
\hline Hospitalised during pregnancy (days) & \\
\hline 0 & 6 \\
$1-7$ & 2 \\
$\geq 8$ & 2 \\
\hline Hospitalised on maternity ward postpartum (days) \\
$\leq 2$ & 3 \\
\hline $3-6$ & 5 \\
$\geq 7$ & 2 \\
\hline Hospitalised on NICU postpartum (days) \\
0 & 5 \\
$1-7$ & 1 \\
$\geq 8$ & 4 \\
\hline
\end{tabular}

*Non-pregnancy-related disorders.

NICU, neonatal intensive care unit.

I had very low expectations, actually, because I didn't even know who I was supposed to be having the consultation with-I couldn't work it out. Not necessarily in terms of specific people, but not in terms of specialist group either. Because I thought, I haven't been assigned to anyone, there's no one on the maternity ward, certainly no one I can think of; there's no obstetrician or whoever that I can think of. I knew some of the doctors from the neonatal ward, but they
Table 3 Conditions experienced by the interviewed women and partners

\begin{tabular}{|c|c|c|}
\hline Condition* & & \\
\hline Bladder injury & 1 Woman & 1 Partner \\
\hline $\begin{array}{l}\text { Emergency caesarean } \\
\text { section }\end{array}$ & 6 Women & 3 Partners \\
\hline $\begin{array}{l}\text { Postpartum } \\
\text { haemorrhage }\end{array}$ & 3 Women & 2 Partners \\
\hline Placental abruption & 2 Women & 0 Partner \\
\hline Preterm delivery & 5 Women & 3 Partners \\
\hline Preeclampsia & 2 Women & 1 Partner \\
\hline PPROM & 2 Women & 1 Partner \\
\hline
\end{tabular}

*Some women had multiple morbidities, so they appear in more than one category.

PPROM, preterm premature rupture of membranes.

weren't at the birth because they are... I just found it hard to place. (Victoria)

Most of the women preferred the obstetrician to initiate the consultation with a review of their clinical notes to receive a detailed clinical description of the events. Analysing the participants narratives, it was evident that they longed for a professional reflection on the occurred events. To the participants, the consultation constituted a space for attributing meaning to and ordering of the chaotic perinatal events. They expressed a strong need to have their own perception of a rather critical pregnancy, birth or postpartum period confirmed by the obstetrician. Some women described feeling confused and disoriented about what happened. They had a feeling of being both present and absent at their birth. The ObPostCons facilitated the woman and the obstetrician to obtain a shared narrative of the occurred events and it succeeded in helping them make sense of the chaotic events.

Getting what actually went on to fit with how I experienced the atmosphere-because to me, in my head, it really felt like the atmosphere was tense ... I think that was kind of what I imagined working through with her. I wanted confirmation that it was pretty intense right up to the end. (Sarah)

In some cases, the ObPostCons did not live up to the participants expectations. One partner had hoped that the ObPostCons would bring him and his wife a sense of justice and acknowledgement of what they had experienced but was not met in his need.

To me it feels a little bit like, they don't really apologise, professionally I mean. They explain to you what happened and that they want to tighten up, but, you know, I do feel that in a way they could let you know that it probably should have been done differently. (Jacob) 


\section{A need for relational continuity}

Most of the women emphasised the importance of knowing the obstetrician who conducted the ObPostCons. However, none of the partners mentioned the relational continuity as important.

The obstetrician became an important person in the women's story, and the relational continuity seemed pivotal to the women's experience of the ObPostCons. It was essential that the obstetrician who was going to review their perinatal events had been present or involved in their care and hence knew what had happened.

It was good to talk to specialists who had actually been present about my experiences. (Tracy)

Most of the participants had the ObPostCons with an obstetrician whom they had met before, either in pregnancy at the outpatient clinic or at the hospital during pregnancy, birth or postpartum period. However, only one woman did not know the obstetrician present at the ObPostCons. She expressed how disappointed she was not to see the obstetrician at the ObPostCons that she had specifically requested to see.

Well, I had my consultation with another doctor, and I thought, hmm right ... o.k. And I could feel how I was already thinking: what should I talk to her about? I just couldn't see why I should be having the consultation with a completely different doctor. (Sarah)

It was important that the obstetrician knew their story well, so that they did not have to start from scratch when presenting their interpretation of the events. Most of the participants felt that knowing the obstetrician was meaningful because it was someone they trusted and felt safe about confiding in. One woman viewed talking to the obstetrician as a way of creating continuity and order in the emotional chaos she happened to be in.

You just need some sort of continuity in that kind of chaotic process. Where you don't need to communicate the whole time. It's chaotic enough already. ... So, seeing the same face, someone who takes the time ... that was so important. I'd say to anyone who has to go through that kind of process that it's really nice if the same person can accompany you through it, like Heather does with me now. The doctor for the postnatal consultation. (Emily)

\section{The importance of discussing emotional effects as well as physical aspects of occurred events}

Many of the participants described a need to discuss the more psychological aspects of their experience and more specifically how it had affected them emotionally.

They didn't ask me so much about how I felt. My feelings about what had happened. They might well ask about that. Or, if they had time and the opportunity to ask because, you know, it would, like, take time. (Lily)
Some of the women explained how the ObPostCons did not succeed in creating a confidential space for discussions about what had been difficult emotionally. One woman arrived at the ObPostCons with no expectations of talking about how she had experienced the birth. Yet, she wondered if she might have opened up emotionally had the obstetrician asked her questions about her emotional state. Moreover, the physical surroundings and the obstetrician's attitude played a crucial role for her desire to open up for emotional difficulties.

It would be worth putting some thought into what sort of questions the doctor needs to ask to open up some of these issues. Because it's one thing just coming in and saying I'd like to hear what you think about how it went generally, but if she had asked specific questions, other aspects might have also cropped up. ... You shouldn't underestimate what effect the room you're sitting in has on you. I mean, how would I have responded if she'd sat me down on a couch? And if I'd thought I had $45 \mathrm{~min}$ instead of 20? (Sophie)

In contrast, one of the women had hoped for a review of how she was feeling emotionally, but her expectations were not met. Yet, her story of the ObPostCons was characterised by an uncertainty. She did not feel comfortable enough to address the need for questions relating to aspects of her mental well-being. She would have preferred if the obstetrician had asked her more specific questions relating to her emotional state at the time.

'Yeah ... deep conversation about how I felt during that time. During the time I was in pain. If I felt lonely, if I felt kind of isolated. I think it's important to know if the mother is feeling okay because it can be-what's it called-she can be affected, the mother, the whole life. It can affect her.' .... 'Questions like how did you feel during those days? First day, second day, third day. Was the feeling getting too much? Something like that.' (Cecille)

However, when the obstetrician did actually encourage discussions of emotional aspects, the participants were positively surprised.

I also remember the obstetrician asked me about the mental aspects and she said that it was possible to have a kind of mental reaction after the birth and I thought that was actually really nice-the fact that, even though she was a doctor, she also focused on the fact that it wasn't just about the physical aspects. (Laura)

\section{Preparing for future pregnancies}

After having reviewed their perinatal experiences, the participants turned their focus on the future. They expressed an urge to acquire more information on how they or the healthcare professionals could prevent their story from repeating itself in a future pregnancy. They 
also liked to be reassured about a safety net and extra care plan being offered during subsequent pregnancies.

I also think it's nice to know that if I choose to get pregnant again some other time, they'll keep an eye on me-there'll be more scans and things like that. I mean, they might have been able to do something if I'd had the weight scan a bit earlier. (Tracy)

One partner, after having experienced a preterm birth, expressed how the ObPostCons served as a kind of preparatory consultation for potential subsequent pregnancies.

We were more interested in looking ahead, and that was really what it was about and what Emily and I talked about-what we would do the next time. How ... we make sure we don't end up in this situation again (Thomas)

\section{Closure of the story}

Analysing the narratives provided a novel, more nuanced understanding of what is conventionally understood as the conception, birth and coming into being of a child and a family. The study participants described how the childbirth experience began long before and continued long after the actual act of giving birth.

While the ObPostCons was seen as a preparation for future pregnancies, the analysis also revealed how the ObPostCons for many women and partners provided a closure of the embarking on becoming a family. During the ObPostCons the women and their partners had their experiences from the perinatal events processed and their attention was directed towards future pregnancies.

It was a good way of rounding off-I felt like it was a kind of closure. (Emily)

Obstetricians conducting the ObPostCons were seen as mediators in the participants' process of attributing meaning to a chaotic course of perinatal events. Moreover, receiving acknowledgement from the obstetrician for what they had been through amplified the sense of closure.

It is a good thing to get that closure of it. Like, there were some specialists who've done it before and who've carried out loads of emergency caesareans and who can say: you know, if you feel a bit exhausted now and over the next few days, weeks or months, that's perfectly normal. Because what you've been through is pretty tough! (James)

Overall, the ObPostCons was seen as a means to understand what had actually happened, serving as a way to obtain a positive closure in terms of their birthing story and building confidence for potential future pregnancies and the beginning of a new chapter in their life.

\section{DISCUSSION}

This narrative study highlights, from women's and partners' perspectives, some important aspects of how and when these consultations may be conducted in a meaningful way.

The analyses indicated the importance of being informed about the purpose of the postnatal consultation and having met the obstetrician before, preferably during the critical perinatal events. They wanted the obstetrician's description of what occurred, and they urged to have the healthcare professional confirm their own perceptions of a critical or chaotic event. Furthermore, they emphasised a need to discuss the more emotional aspects of the experience.

\section{Strengths and limitations}

One of the strengths of this study was a short time interval from the ObPostCons to the interview, enhancing the participants' ability to recall their experiences during ObPostCons.

The women and their partners were interviewed individually in separate rooms, providing the space for them to present their own uninterrupted narrative. The transdisciplinary nature of the group also enhanced the reflexivity and validity of the study.

The data collected in this study were from a heterogeneous group. However, our study did not aim to target all perinatal complications. Women and partners who had experienced perinatal death were excluded from this study, but in Denmark women and partners who experience perinatal deaths are all routinely offered an ObPostCons. This group may have different needs, making this a focus for future studies.

Our study sample was relatively small due to prioritising in-debt knowledge on lived experience.

\section{Interpretation}

Expectations towards the ObPostCons differed, ranging from purely factual explanations of what happened to exploring deeper emotional issues, experiences and mental well-being, which was also evident in other studies. ${ }^{417}$ The participants longed for the obstetrician to mirror their perception and understanding of the level of complications and complexity of their critical perinatal experience but at the same time to have a detailed clinical description of the occurred events. This shows how intersubjective and mutual agreement on the course of events provided the women/partners with an experience of being heard, despite differences between their own and the healthcare professional's understanding of the course of the events. ${ }^{25}$ During the consultation the obstetrician and the woman/partner created a shared narrative of the perinatal experience. These findings are in line with previous studies that also stress the importance of women and their partners to have an opportunity to talk about their experiences after childbirth and to be given information about how the healthcare professional categorised their experience in terms of degree of danger and urgency. ${ }^{17}$ 27-29

In line with previous findings, our study indicated that especially the women found the relational continuity as 
essential when attending the ObPostCons. ${ }^{27} 28$ Moreover, trust, continuity and consistency in the healthcare team provided the participants with a sense of predictability and coherence.

Our findings reflect how critical perinatal stories provide a framework for sense-making when organised into narratives and how the intersubjective aspects of narrative medicine can be used to enhance the healing process. ${ }^{25} 30$ The women and their partners used the ObPostCons to structure, make sense of and to remaster their experiences by telling their stories and filling in gaps. ${ }^{25}$ The women and their partners emphasised that the ObPostCons helped giving closure to their story of becoming parents. Our findings encapsulate and are supported by the theory of patient centred care in which the patients' overall care experiences are shaped by the network of practices, interactions, relationships, shared meanings as well as the physical elements. ${ }^{31}$

In terms of future pregnancies, childbirth and overall well-being, this study adds to the literature of the importance of women and partners having embraced, processed and acquired a full understanding of their experience of critical perinatal events. ${ }^{32-34}$ Our findings suggest that the ObPostCons plays an important role in this process for most women and some partners. However, only four of the seven partners interviewed had attended the ObPostCons. The need to attend the ObPostCons was equivocal. Some of the partners expressed no personal need to participate in the ObPostCons and did it mainly to support their partner while others thought it was valuable. Previous research has shown that partners often feel overlooked in the perinatal period and that the healthcare professionals focus exclusively on the women and babies. ${ }^{12} 18$ Our findings did not indicate that the partners felt marginalised in relation to the ObPostCons. However, future research may benefit from including more on partners' perspective. It would be interesting to better understand why some partners in some cases did not wish to attend the ObPostCons.

The clinical implications of the study include that the women and their partners are informed about the purpose, the time allocated and the structure of the ObPostCons. Furthermore, our findings suggest that it is important to assign a known obstetrician and to pay attention to the women's and their partners' mental wellbeing. The ObPostCons also needs to be flexible enough to fit in around other commitments, for example, work, to make participation possible for the partners.

\section{CONCLUSION}

This study indicates that ObPostCons is important to women in the process of adapting to their critical perinatal experiences. However, the study findings suggest that the structure, organisation and content of the ObPostCons need to be improved.

There is a need for further research exploring more on the partners' perspective and to explore if there are any differences or similarities between the women's and their partners' needs. Future research may investigate the optimal timing for ObPostCons and how to achieve an environment that gives the woman and their partners the confidence to discuss the more emotional aspects of what they experienced. To make a comprehensive analysis of the ObPostCons, future studies may benefit from exploring the interaction between the obstetrician and the women and their partners at the consultation. Finally, there is a need for future studies evaluating different interventions aimed at guiding women and their partners at the ObPostCons.

\section{Author affiliations}

${ }^{1}$ Department of Obstetrics, Rigshospitalet, Copenhagen, Denmark

${ }^{2}$ The Danish Centre for Social Science Research, VIVE, Copenhagen, Denmark

${ }^{3}$ Public Health, Faculty of Health Sciences, University of Copenhagen, Kobenhavn, Denmark

${ }^{4}$ Juliane Marie Centre for Children, Women and Reproduction Section 4074

Rigshospitalet, University of Copenhagen, Copenhagen, Denmark

Acknowledgements We would like to thank the women and their partners who participated in this study and for openly sharing their experiences with us. We are also especially grateful to the auxiliary nurses and obstetricians in the outpatient clinic for their immense help in recruiting the participants.

Contributors JLS created the idea for the project. SH, LEN, MJ, MNS and JLS designed the study. SH and LEN were responsible for conducting the interviews. SH was responsible for obtaining data from patient records. SH drafted the manuscript, with contributions on interpretation of data and critical revision of important intellectual content from LEN, MJ, MNS and JLS. All authors reviewed and approved the final manuscript for publication.

Funding The non-profit Danish Regions Development and Research Foundation provided most of the funding for this study.

Competing interests None declared.

Patient and public involvement Patients and/or the public were involved in the design, or conduct, or reporting, or dissemination plans of this research. Refer to the Methods section for further details.

\section{Patient consent for publication Not required.}

Ethics approval Approvals from the Capital Region's Committee on Health Research Ethics (file no. 62217, approval date 23/2/2018) and the Danish Data Protection Agency (file no. VD-2018-103, approval date 3/5/2018) were obtained. The information letter stressed how participation was voluntary and that findings would be written without participants being identifiable. Participating in the study did not affect the treatment and care of the participants.

Provenance and peer review Not commissioned; externally peer reviewed.

Data availability statement No data are available. The datasets analysed for the current study are not publicly available, as participants were not asked to consent to the sharing of the data at the time of data collection.

Open access This is an open access article distributed in accordance with the Creative Commons Attribution Non Commercial (CC BY-NC 4.0) license, which permits others to distribute, remix, adapt, build upon this work non-commercially, and license their derivative works on different terms, provided the original work is properly cited, appropriate credit is given, any changes made indicated, and the use is non-commercial. See: http://creativecommons.org/licenses/by-nc/4.0/.

\section{ORCID iDs}

Stinne Høgh http://orcid.org/0000-0002-8712-1088

Laura Emdal Navne http://orcid.org/0000-0001-8996-3222

\section{REFERENCES}

1 Sundhedsstyrelsen. Anbefalinger for svangreomsorgen. Copenhagen, 2013. 
2 National Institute for Health and Care Excellence. Postnatal care up to 8 weeks after birth.Clinical guideline, 2006.

3 Helsedirektoratet. Nytt liv OG trygg barseltid for familien. Nasjonal faglig retningslinje for barselomsorgen. Oslo, 2014.

4 Carlgren I, Berg M. Postpartum consultation: occurrence, requirements and expectations. BMC Pregnancy Childbirth 2008;8:29.

5 McLachlan HL, Gold L, Forster DA, et al. Women's views of postnatal care in the context of the increasing pressure on postnatal beds in Australia. Women Birth 2009;22:128-33.

6 Furuta M, Sandall J, Bick D. Women's perceptions and experiences of severe maternal morbidity--a synthesis of qualitative studies using a meta-ethnographic approach. Midwifery 2014;30:158-69.

7 Hinton L, Locock L, Knight M. Maternal critical care: what can we learn from patient experience? A qualitative study. BMJ Open 2015;5:e006676.

8 Elmir R, Schmied V, Wilkes L, et al. Women's perceptions and experiences of a traumatic birth: a meta-ethnography. J Adv Nurs 2010;66:2142-53.

9 Räisänen S, Lehto SM, Nielsen HS, et al. Fear of childbirth predicts postpartum depression: a population-based analysis of 511422 singleton births in Finland. BMJ Open 2013;3:e004047.

10 Steegers EAP, von Dadelszen P, Duvekot JJ, et al. Pre-Eclampsia. Lancet 2010;376:631-44.

11 Leahy-Warren P, McCarthy G, Corcoran P. First-Time mothers: social support, maternal parental self-efficacy and postnatal depression. $J$ Clin Nurs 2012;21:388-97.

12 Lever Taylor B, Billings J, Morant N, et al. Experiences of how services supporting women with perinatal mental health difficulties work with their families: a qualitative study in England. BMJ Open 2019;9:e030208.

13 Elmir R, Schmied V. A meta-ethnographic synthesis of fathers' experiences of complicated births that are potentially traumatic. Midwifery 2016;32:66-74.

14 Hinton L, Locock L, Knight M. Partner experiences of "near-miss" events in pregnancy and childbirth in the UK: a qualitative study. PLoS One 2014;9:e91735.

15 Bastos MH, Furuta M, Small R, et al. Debriefing interventions for the prevention of psychological trauma in women following childbirth. Cochrane Database Syst Rev 2015;4:CD007194.

16 Olin R-M, Faxelid E. Parents' needs to talk about their experiences of childbirth. Scand J Caring Sci 2003;17:153-9.

17 Hinton L, Locock L, Knight M. Experiences of the quality of care of women with near-miss maternal morbidities in the UK. BJOG 2014;121 Suppl 4:20-3.

18 Lever Taylor B, Billings J, Morant N, et al. How do women's partners view perinatal mental health services? A qualitative meta-synthesis. Clin Psychol Psychother 2018;25:112-29.
19 Mattingly C, Lawlor M. Learning from stories: narrative interviewing in cross-cultural research. Scand J Occup Ther 2000;7:4-14.

20 Charon R. The principles and practice of narrative medicine. New York: Oxford University Press, 2017.

21 National Health Data Authority. Medical birth registry. Available: https://sundhedsdatastyrelsen.dk/da/registre-og-services/omde-nationale-sundhedsregistre/graviditet-foedsler-og-boern/ foedselsregisteret [Accessed 11 Apr 2018].

22 Crabtree B, Miller W. Doing qualitative research. London: Sage Publications Inc, 1999

23 Navne LE, Svendsen MN, Gammeltoft TM. The attachment imperative: parental experiences of Relation-making in a Danish neonatal intensive care unit. Med Anthropol Q 2018;32:120-37.

24 Navne LE, Svendsen MN. A clinical Careography: steering Life-anddeath decisions through care. Pediatrics 2018;142:S558-66.

25 Jackson M. Minima ethnographica: intersubjectivity and the anthropological project. United States of America: The University of Chicago Press, 1998.

26 Madden R. Being ethnographic: a guide to the theory and practice of ethnography. California: Sage Publication, 2010.

27 Barimani M, Vikström A. Successful early postpartum support linked to management, informational, and relational continuity. Midwifery 2015;31:811-7.

28 Tham V, Ryding EL, Christensson K. Experience of support among mothers with and without post-traumatic stress symptoms following emergency caesarean section. Sex Reprod Healthc 2010;1:175-80.

29 Kvist LJ, Persson EK. Evaluation of changes in postnatal care using the "Parents' Postnatal Sense of Security" instrument and an assessment of the instrument's reliability and validity. BMC Pregnancy Childbirth 2009;9:35.

30 Mattingly C. Healing Dramas and clinical plots. The narrative structure of experience. New York: Cambridge University Press, 1998.

31 Liberati EG, Gorli M, Moja L, et al. Exploring the practice of patient centered care: the role of ethnography and reflexivity. Soc Sci Med 2015;133:45-52.

32 Grekin R, O'Hara MW. Prevalence and risk factors of postpartum posttraumatic stress disorder: a meta-analysis. Clin Psychol Rev 2014;34:389-401.

33 de Graaff LF, Honig A, van Pampus MG, et al. Preventing posttraumatic stress disorder following childbirth and traumatic birth experiences: a systematic review. Acta Obstet Gynecol Scand 2018;97:648-56.

34 Hinton L, Locock L, Knight M. Support for mothers and their families after life-threatening illness in pregnancy and childbirth: a qualitative study in primary care. Br J Gen Pract 2015;65:e563-9. 